\title{
Upstream deregulation of calcium signaling in Parkinson's disease
}

\section{Pilar Rivero-Ríos, Patricia Gómez-Suaga, Elena Fdez and Sabine Hilfiker*}

Instituto de Parasitología y Biomedicina "López-Neyra," Consejo Superior de Investigaciones Científicas, Granada, Spain

\section{Edited by:}

Kirsten Harvey, University College

London, UK

\section{Reviewed by:}

Baojin Ding, University of

Massachusetts Medical School, USA

Marisa Brini, University of Padova,

Italy

\section{*Correspondence:}

Sabine Hilfiker, Instituto de

Parasitología y Biomedicina

"López-Neyra," Consejo Superior de Investigaciones Científicas, Avda del Conocimiento s/n, 18016 Granada, Spain

e-mail: sabine.hilfiker@ipb.csic.es
Parkinson's disease (PD) is a major health problem affecting millions of people worldwide. Recent studies provide compelling evidence that altered $\mathrm{Ca}^{2+}$ homeostasis may underlie disease pathomechanism and be an inherent feature of all vulnerable neurons. The downstream effects of altered $\mathrm{Ca}^{2+}$ handling in the distinct subcellular organelles for proper cellular function are beginning to be elucidated. Here, we summarize the evidence that vulnerable neurons may be exposed to homeostatic $\mathrm{Ca}^{2+}$ stress which may determine their selective vulnerability, and suggest how abnormal $\mathrm{Ca}^{2+}$ handling in the distinct intracellular compartments may compromise neuronal health in the context of aging, environmental, and genetic stress. Gaining a better understanding of the varied effects of $\mathrm{Ca}^{2+}$ dyshomeostasis may allow novel combinatorial therapeutic strategies to slow PD progression.

Keywords: Parkinson's disease, dopamine, calcium, mitochondria, endoplasmic reticulum, Iysosomes, Golgi

\section{INTRODUCTION - WHICH NEURONS DIE IN PD?}

Parkinson's disease (PD) is an incurable late-onset neurodegenerative disorder which is strongly associated with aging, as evidenced by the exponential increase in incidence above the age of 65 (de Rijk etal., 1997; de Lau etal., 2004). Due to extended life expectancy, the prevalence of PD is estimated to double by 2030. Therefore, deciphering the molecular mechanisms underlying the disease, with the aim of developing novel disease-modifying therapies, has become an urgent and crucial task in PD-related research. Whilst PD is a disease of neurons, not all neurons are affected. The motor symptoms of PD, such as resting tremor, bradykinesia, and rigidity are clearly linked to the death of dopamine (DA) neurons in the substantia nigra pars compacta $(\mathrm{SNc})$. Similarly, the clinical gold-standard treatment of L-DOPA (3,4-dihydroxy-Lphenylalanine), a DA precursor, indicates that DA neurons are crucial to the disease. However, the neuropathological hallmarks of $\mathrm{PD}$, which are the presence of proteinaceous intracellular deposits called Lewy bodies or Lewy neurites in surviving neurons, are more distributed and not exclusive to DA neurons. Non-DA neurons which show pathology in PD include cholinergic neurons in the dorsal motor nucleus of the vagus (DMV) and basal forebrain $(\mathrm{BF})$, noradrenergic neurons in the locus ceruleus (LC), and serotonergic neurons in the raphe nuclei (RN; Braak etal., 2004). Neurodegeneration is also not evident in all dopaminergic neuronal populations. For example, DA neurons in the ventral tegmental area (VTA) are relatively unaffected (Matzuk and Saper, 1985; Kish et al., 1988; Ito et al., 1992; Damier et al., 1999). Thus, elucidating why the diverse neurons are at risk for degeneration is essential if we want to formulate testable hypotheses as to the cause(s) underlying PD.

\section{WHY DO NEURONS DIE IN PD - FROM DOPAMINE TO MITOCHONDRIA}

Distinct mechanisms have been proposed to account for the preferential loss of DA neurons in PD. One hypothesis proposed that DA itself may be the culprit, as oxidation of cytosolic DA and its metabolites can lead to the production of cytotoxic free radicals and oxidative stress (Greenamyre and Hastings, 2004). However, since not all dopaminergic neurons are at risk in $\mathrm{PD}$, and since elevating DA levels in PD patients by L-DOPA administration does not accelerate the progression of PD (Fahn, 2005), DA unlikely is the principal culprit, even though its effects may further worsen the cellular deficits related to oxidant stress and/or protein aggregation triggered by other means (see below).

Another hypothesis has linked PD to mitochondrial dysfunction (Henchcliffe and Beal, 2008; Schapira, 2008; Vila et al., 2008). Mitochondria are crucial organelles for cellular energy production. The transport of electrons down the electron transport chain (ETC) releases energy which is used by complex I, III, and IV to pump protons from the mitochondrial matrix to the mitochondrial intermembrane space, creating a proton gradient and an electrochemical gradient across the mitochondrial inner membrane, the latter of which is being used by ATP synthase to convert ADP to ATP. Mitochondria comprise one of the major cellular producers of reactive oxygen species (ROS), as electrons in the ETC are occasionally captured by oxygen to produce superoxide anion radicals, with complex I and III being the major culprits for production of these radicals (Cali et al., 2011).

There is extensive evidence for mitochondrial involvement in both sporadic and genetic PD. Toxins such as MPTP, rotenone, and paraquat, which inhibit complex I, can cause a Parkinsonian 
phenotype (Betarbet et al., 2000; Przedborski et al., 2004). In addition, postmortem tissue samples derived from the SNc from sporadic PD patients display a drastic decrease in the activity of complex I (Mann etal., 1994). A deficit in ETC can cause mitochondria-derived oxidative stress in the form of ROS and other radicals. Indeed, the decreased activity of complex I in PD patients seems due to oxidative damage (Keeney et al., 2006) and also affects other cellular components such as lipids and DNA (Zhang etal., 1999). Oxidative damage may also be responsible for the high levels of somatic mitochondrial DNA (mtDNA) deletions in SNc DA neurons (Bender etal., 2006; Kraytsberg etal., 2006), and the physical proximity of mtDNA to the site of ROS generation may indeed make them a vulnerable target. Since seven proteins involved in the formation of complex I are encoded by the mitochondrial genome, this may give rise to further ETC dysfunction and oxidative stress, leading to accelerated loss of SNc DA neurons.

However, the observed decrease in complex I deficiency in homogenates from nigral tissue from PD patients is too big to be restricted to SNc DA neurons, and only a proportion of PD patients show complex I inhibition in the SNc (Jenner, 2001). In addition, whilst toxins such as the herbicide rotenone cause ubiquitous complex I inhibition, dopaminergic degeneration is observed in the SNc, but not in the VTA area (Betarbet et al., 2000). Thus, inhibition of mitochondrial complex I activity per se cannot explain the selective vulnerability of neurons which die in PD.

\section{WHY DO NEURONS DIE IN PD - PACEMAKING, $\mathrm{Ca}^{2+}$ DYSHOMEOSTASIS, AND OXIDANT STRESS}

A hypothesis, put forward by Surmeier's group, suggests that specific and shared physiological features are responsible for the risk of a subset of neurons to degenerate in PD (Guzman et al., 2010; Surmeier et al., 2011; Goldberg et al., 2012), and comprises probably the best working model to explain disease pathomechanism to date (Figure 1).

Neurons are electrically excitable, using steep electrochemical gradients (mainly $\mathrm{Na}^{+}$and $\mathrm{K}^{+}$gradients) across their plasma membrane to integrate incoming chemical signals, and pass them on to other neurons. Voltage-dependent $\mathrm{Ca}^{2+}$ channels in most neurons are only opened by strong depolarization during an action potential. These channels close relatively slowly during membrane repolarization, such that the total $\mathrm{Ca}^{2+}$ influx during a spike is very sensitive to spike duration. To minimize global increases in $\mathrm{Ca}^{2+}$, neurons which need to spike at high frequencies tend to restrict $\mathrm{Ca}^{2+}$ entry by keeping spikes very brief, and tend to express $\mathrm{Ca}^{2+}$ buffering proteins to help manage intracellular $\mathrm{Ca}^{2+}$ levels (Augustine et al., 2003).

In contrast to many other neurons, SNc DA neurons are autonomously active in the absence of synaptic input (Grace and Bunney, 1983). Such pacemaking activity is necessary to maintain a basal DA tone in the striatum; without it, movement ceases (Surmeier and Schumacker, 2013). Whilst most neurons rely on $\mathrm{Na}^{+}$to drive this pacemaking activity, SNc DA neurons also engage L-type $\mathrm{Ca}^{2+}$ channels with a Cav1.3 pore-forming subunit (Bonci et al., 1998; Puopolo et al., 2007). Although not strictly necessary for pacemaking, L-type $\mathrm{Ca}^{2+}$ channels help support pacemaking (Guzman et al., 2009). SNc DA neurons exhibit slow, broad spikes, causing a significant increase in intracellular $\mathrm{Ca}^{2+}$ levels, and they lack relevant intrinsic $\mathrm{Ca}^{2+}$ buffering capacity (Foehring et al., 2009; Guzman et al., 2009). The combination of these features, namely spontaneous activity that can be intrinsically generated, broad action potentials, prominent $\mathrm{Ca}^{2+}$ currents and low intrinsic $\mathrm{Ca}^{2+}$ buffering capacities are common to all neurons at risk for neurodegeneration in PD, irrespective of their neurotransmitter content (Surmeier and Schumacker, 2013). In contrast, relatively non-affected VTA DA neurons, whilst also slow pacemaking neurons, have low L-type $\mathrm{Ca}^{2+}$ channel densities and express high levels of the $\mathrm{Ca}^{2+}$ buffering protein calbindin (German etal., 1992; Khaliq and Bean, 2010).

\section{GETTING RID OF $\mathrm{Ca}^{2+}$ - AN ENERGETICALLY COSTLY PROCESS}

The shared physiological phenotype of at-risk neurons means that they will have a larger burden to handle increased intracellular $\mathrm{Ca}^{2+}$ levels. As $\mathrm{Ca}^{2+}$ is a universal second messenger, controlling a wide variety of cellular events ranging from regulation of enzyme activity to programmed cell death, it is under tight homeostatic control (Petersen et al., 2005). Pumping $\mathrm{Ca}^{2+}$ out of the cytosol is an energy-consuming process. Cytosolic $\mathrm{Ca}^{2+}$ levels are set to around $100 \mathrm{nM}$, which is 20,000-fold lower than the $\mathrm{Ca}^{2+}$ concentration in the extracellular space. This contrasts with the concentration differences of $\mathrm{Na}^{+}$and $\mathrm{K}^{+}$ions across the plasma membrane, which is in the range of $10-30$-fold. Thus, thermodynamic considerations dictate that it will be energetically much more expensive to move $\mathrm{Ca}^{2+}$ ions across the plasma membrane as compared to $\mathrm{Na}^{+}$or $\mathrm{K}^{+}$ions (Surmeier and Schumacker, 2013).

$\mathrm{Ca}^{2+}$ ions are removed from the cytosol by either exchangers or pumps. Exchangers, such as the $\mathrm{Na}^{+} / \mathrm{Ca}^{2+}$ exchanger use the $\mathrm{Na}^{+}$ gradient to move $\mathrm{Ca}^{2+}$ ions out of the cytosol. Pumps, such as the plasma membrane $\mathrm{Ca}^{2+}$-ATPase, use ATP to drive the movement of ions against a concentration gradient. $\mathrm{Ca}^{2+}$ buffering proteins further help to decrease the free $\mathrm{Ca}^{2+}$ concentration. Importantly, $\mathrm{Ca}^{2+}$ which is not rapidly pumped out of the neuron is sequestered into intracellular organelles including the endoplasmic reticulum (ER), mitochondria, Golgi, and lysosomes (Figure 1; Berridge et al., 2000; Rizzuto, 2001; Pinton et al., 2008; Lloyd-Evans and Platt, 2011; Kaufman and Malhotra, 2014).

How the increased demand for $\mathrm{Ca}^{2+}$ handling causes increased risk for degeneration of the vulnerable neuronal populations remains to be fully elucidated. One hypothesis proposes that due to their high basal ATP consumption rates related to $\mathrm{Ca}^{2+}$ handling, vulnerable neurons will have a lesser bioenergetic or respiratory reserve, which is defined as the difference between the maximum capacity for ATP generation by oxidative phosphorylation and the basal ATP consumption rate (Nicholls, 2008). A smaller respiratory reserve may put these neurons at risk when their metabolic demands increase, such as during bursts of spiking or upon toxin exposure. Indeed, when ATP levels are not sufficient to meet demands, a deterioration of the membrane potential would be followed by massive $\mathrm{Ca}^{2+}$ influx and cell death. 


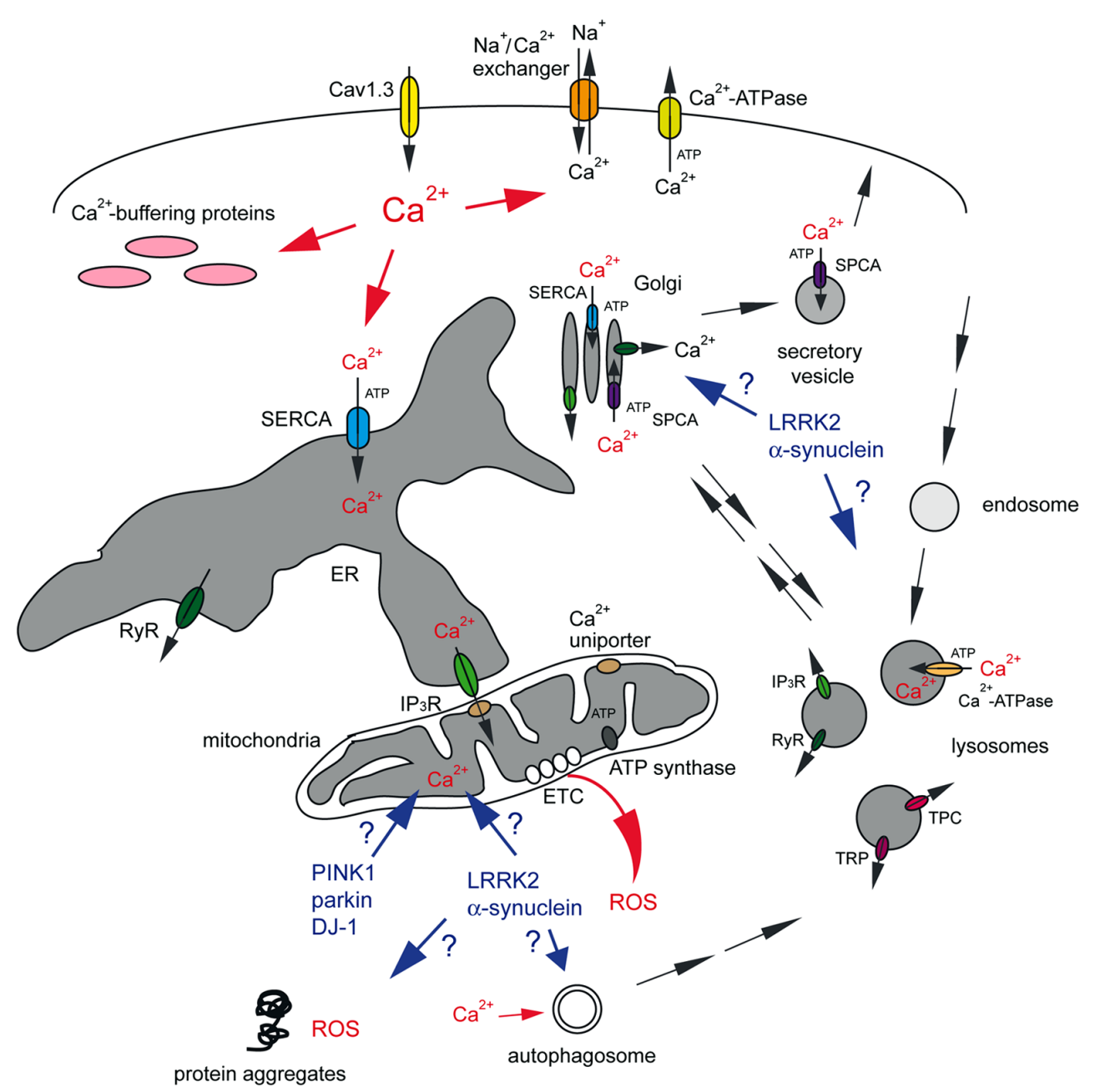

FIGURE 1 | Abnormal $\mathrm{Ca}^{2+}$ signaling in SNc DA neurons may cause mitochondrial oxidant stress, proteostasis deficits and eventual cell death. Vulnerable neuronal populations display spontaneous slow pacemaking activity employing Cav1.3 L-type $\mathrm{Ca}^{2+}$ channels, prominent $\mathrm{Ca}^{2}+$ currents and low intrinsic $\mathrm{Ca}^{2}+$ buffering capacities. $\mathrm{Ca}^{2+}$ inside the neuron can be transported back across the plasma membrane either via plasma membrane $\mathrm{Ca}^{2+}$-ATPase at the cost of ATP consumption, or through the $\mathrm{Na}^{+} / \mathrm{Ca}^{2+}$ exchanger which uses the $\mathrm{Na}^{+}$gradient across the plasma membrane. $\mathrm{Ca}^{2+}$ is rapidly sequestered by interactions with $\mathrm{Ca}^{2+}$ buffering proteins or taken up into a variety of intracellular organelles. The ER uses a high-affinity $\mathrm{Ca}^{2+}$-ATPase [the sarco-endoplasmic reticulum $\mathrm{Ca}^{2+}$-ATPase (SERCA)] to pump $\mathrm{Ca}^{2}+$ into the ER lumen at the cost of ATP consumption. This pump is also present on cis and medial Golgi membranes, whilst secretory vesicles employ a secretory pathway $\mathrm{Ca}^{2+}$-ATPase (SPCA) which is also be present on the trans Golgi complex. $\mathrm{Ca}^{2}+$ uptake into acidic organelles is mediated by a molecularly unidentified $\mathrm{Ca}^{2+}$-ATPase. $\mathrm{Ca}^{2+}$ flows back into the cytosol from the ER lumen through $I P_{3}$ receptors $\left(I P_{3} R\right)$ or ryanodine receptors (RyR). $I P_{3} R$ are also present on cis and medial Golgi membranes, RyR on trans Golgi membranes, and RyR, TRP and TPC channels are present on acidic organelles. Mitochondria, often in close apposition to the ER or plasma membrane, can take up $\mathrm{Ca}^{2+}$ into the matrix through a mitochondrial $\mathrm{Ca}^{2+}$ uniporter. $\mathrm{Ca}^{2+}$ transfer between $\mathrm{ER}$ and mitochondria involves the $I P_{3} R$ on the ER membrane. $\mathrm{Ca}^{2+}$ within mitochondria is necessary for proper ETC function to generate ATP by ATP synthase, but mitochondrial $\mathrm{Ca}^{2+}$ overload can cause mitochondrial oxidant stress (ROS). Toxins as well as familial mutations in PINK1, parkin and DJ-1 affect mitochondrial ATP production and $\mathrm{Ca}^{2+}$ handling, even though the molecular details remain to be determined. The effects of familial mutations in LRRK2 and $\alpha$-synuclein on mitochondrial functioning are even less clear, but those mutant proteins may cause additional deficits in proteostasis through mechanisms involving $\mathrm{Ca}^{2+}$-regulated events such as autophagy. This may also include alterations in the trafficking of Golgi-derived vesicles to the plasma membrane, resulting in changes in vesicle secretion and in the steady-state levels of surface receptors. Golgi deficits may cause altered trafficking of enzymes destined to lysosomes, with concomitant deficits in lysosomal degradative capacity, or alterations in retromer-mediated retrieval from endolysosomes back to the Golgi. Finally, changes in acidic store $\mathrm{Ca}^{2+}$ levels may affect various endo-lysosomal trafficking steps or the degradative capacity of acidic organelles per se. For further details see text.
The increased metabolic demand of SNc neurons may also give rise to an increase in the basal level of mitochondrial oxidant stress, as high rates of metabolic activity cause increased ROS production (Figure 1; Lee et al., 2001). In support of this, pacemaking in $\mathrm{SNc}$ neurons was shown to generate mitochondrial oxidant stress, which was not apparent in neighboring VTA DA neurons (Guzman etal., 2010). Such oxidant stress was largely prevented in the presence of L-type $\mathrm{Ca}^{2+}$ channel antagonists, clearly implicating those channels and the resultant increase in intracellular $\mathrm{Ca}^{2+}$ as culprits for downstream oxidant stress 
generated by high demands for mitochondrial ATP production.

Mitochondrial oxidant stress causes mild mitochondrial depolarization or uncoupling (Guzman et al., 2010), which leads to a decline in energy production and generation of ROS, causing damage to proteins, lipid, and DNA. In accordance with this, mtDNA deletions are significantly greater in SNc DA neurons from older as compared to younger subjects, and from neurons from PD patients as compared to unaffected individuals (Bender et al., 2006; Kraytsberg et al., 2006), with no changes observed in other brain areas. The accumulation of mtDNA deletions, with effects on mitochondrial respiratory chain function, will thus lead to further bioenergetic deficiency that manifests over time.

\section{GETTING RID OF $\mathrm{Ca}^{2+}$ - NOT JUST A PROBLEM OF ENERGY}

It is clear that cytosolic $\mathrm{Ca}^{2+}$ levels have to be maintained within a small range of concentrations for optimal survival of SNc DA neurons (Michel et al., 2013). However, apart from the extra bioenergetic burden to control intracellular $\mathrm{Ca}^{2+}$ levels, altered $\mathrm{Ca}^{2+}$ handling by various intracellular organelles may threaten neuronal viability as well. Indeed, mitochondrial oxidant stress in SNc DA neurons can be diminished when limiting mitochondrial $\mathrm{Ca}^{2+}$ uptake, without affecting pacemaking (Guzman et al., 2010). This is important, as it suggests that mitochondrial oxidant stress may be the consequence of increased mitochondrial $\mathrm{Ca}^{2+}$ load, rather than a mere reflection of the need for increased ATP production.

$\mathrm{Ca}^{2+}$ is well-known to modulate mitochondrial function. The $\mathrm{Ca}^{2+}$ uniporter uses the mitochondrial membrane potential to take $\mathrm{Ca}^{2+}$ up into the mitochondrial matrix (Kirichok et al., 2004; Santo-Domingo and Demaurex, 2010), where it increases ATP production by stimulating enzymes of the tricarboxylic acid (TCA) cycle, and thus helps to maintain increased metabolic demands associated with electrical activity and influx of $\mathrm{Ca}^{2+}$ (McCormack and Denton, 1990). However, too much $\mathrm{Ca}^{2+}$ in mitochondria compromises mitochondrial function by causing a transient collapse of the mitochondrial membrane potential (McCormack and Denton, 1990), which thus transiently halts the production of ATP.

The mitochondrial $\mathrm{Ca}^{2+}$ uniporter drives rapid and massive $\mathrm{Ca}^{2+}$ entry at high cytosolic $\mathrm{Ca}^{2+}$ concentrations only thought to be reached in microdomains near plasma membrane $\mathrm{Ca}^{2+}$ channels and $\mathrm{Ca}^{2+}$ release channels on the ER. Indeed, the primary intracellular organelle dealing with $\mathrm{Ca}^{2+}$ homeostasis is thought to be the ER (Berridge, 2002; Verkhratsky, 2005). The ER is responsible for the coordinated production, delivery, and degradation of proteins in a process called proteostasis. It forms a continuous intracellular network which extends throughout the somatodendritic tree (Choi et al., 2006), and contains high-affinity ATP-dependent transporters [(sarco-ER Ca ${ }^{2+}$-ATPase (SERCA)] to move $\mathrm{Ca}^{2+}$ from the cytoplasm into the ER lumen. $\mathrm{Ca}^{2+}$ sequestered in the ER can be released at sites where it can be pumped back across the plasma membrane, or can be used locally to modulate cellular function (Verkhratsky, 2005). The $\mathrm{Ca}^{2+}$ store in the ER is highly interconnected with other intracellular $\mathrm{Ca}^{2+}$ stores, such that $\mathrm{ER} \mathrm{Ca}^{2+}$ dyshomeostasis will affect $\mathrm{Ca}^{2+}$ handling in other organelles as well. For example, inositol 1,4,5-trisphosphate $\left(\mathrm{IP}_{3}\right)$ receptors which reside at direct ER-mitochondrial contacts termed MAMs (mitochondriaassociated ER membranes) allow for direct flux of $\mathrm{Ca}^{2+}$ from ER into mitochondria (Csordas et al., 2006; Rizzuto and Pozzan, 2006; Kaufman and Malhotra, 2014), which may then lead to the mitochondrial $\mathrm{Ca}^{2+}$ overload described above (Figure 1). Indeed, stimulation of $\mathrm{Ca}^{2+}$ release from the ER by ryanodine, accompanied by an increase in cytosolic $\mathrm{Ca}^{2+}$ levels, was found to protect DA neurons from spontaneous or induced neurodegeneration (Guerreiro et al., 2008). Thus, relieving the $\mathrm{Ca}^{2+}$ load in the ER, without significantly causing $\mathrm{Ca}^{2+}$ transfer from ER to mitochondria through $\mathrm{IP}_{3}$ receptors, may prove beneficial to the survival of DA neurons, possibly via preventing ER-mediated mitochondrial $\mathrm{Ca}^{2+}$ overload. Altered $\mathrm{ER} \mathrm{Ca}^{2+}$ concentrations are also associated with altered changes in cytosolic $\mathrm{Ca}^{2+}$ concentration upon ER release, and thus can affect the downstream signaling functions of this organelle (Morikawa et al., 2000; LaFerla, 2002).

Apart from its signaling function, $\mathrm{Ca}^{2+}$ plays an inherently important role for the functioning of the ER by acting as an allosteric regulator of protein processing and folding. Depletion of $\mathrm{ER} \mathrm{Ca}^{2+}$ stores induces ER stress and the unfolded protein response (Paschen and Mengesdorf, 2005). Too much intraluminal $\mathrm{ER} \mathrm{Ca}^{2+}$ may compromise proteostasis as well. For example, L-type $\mathrm{Ca}^{2+}$ channel blockers have been shown to restore folding and lysosomal delivery of mutant lysosomal enzymes responsible for a variety of lysosomal storage diseases (Mu etal., 2008). Similarly, decreasing ER $\mathrm{Ca}^{2+}$ levels by SERCA inhibitors seems to enhance the folding and plasma membrane trafficking of mutant cystic fibrosis transmembrane conductance regulator (CFTR; Egan et al., 2002, 2004). Precise $\mathrm{Ca}^{2+}$ imaging experiments will be required to determine the intraluminal ER $\mathrm{Ca}^{2+}$ levels upon such treatments. Nevertheless, these data indicate that altering $\mathrm{ER} \mathrm{Ca}^{2+}$ homeostasis can have profound effects on folding and trafficking of proteins destined to other subcellular locations including lysosomes and the plasma membrane (Figure 1), with obvious downstream effects both on plasma membrane functioning/signaling and lysosomal degradative capacity.

\section{INTRACELLULAR $\mathrm{Ca}^{2+}$ STORES AND $\mathrm{Ca}^{2+}$ HANDLING: THE NEGLECTED PLAYERS}

In addition to the ER and mitochondria, two other compartments deserve attention as significant intracellular $\mathrm{Ca}^{2+}$ store. The first is the Golgi apparatus, which shares some functions and biochemical markers with the ER. The Golgi complex is a highly dynamic intracellular organelle which processes and sorts membrane proteins derived from the ER to the cell surface, secretory vesicles or lysosomes, and which also receives retrograde transport input. Thus, damage to neuronal Golgi structure can have important functional consequences for protein and vesicular trafficking (Fan et al., 2008). Interestingly, Golgi fragmentation has been observed in nigral neurons from PD patients (Fujita et al., 2006), and recent studies indicate that increased neuronal activity causes reversible Golgi fragmentation in a manner dependent on $\mathrm{Ca}^{2+}$-calmodulin-dependent protein kinase (Thayer et al., 
2013). It will be interesting to determine whether Golgi fragmentation is a shared phenotype of vulnerable neurons in PD, and if it can be modulated by L-type $\mathrm{Ca}^{2+}$ channel antagonists. In addition, it remains to be seen whether neuronal activitydependent Golgi fragmentation causes Golgi-derived $\mathrm{Ca}^{2+}$ release which may alter the spatio-temporal complexity of cellular $\mathrm{Ca}^{2+}$ signaling.

The Golgi complex serves as a bona fide $\mathrm{Ca}^{2+}$ store, containing $\mathrm{Ca}^{2+}$-ATPases, $\mathrm{Ca}^{2+}$ release channels and $\mathrm{Ca}^{2+}$-binding proteins (Figure 1; Scherer et al., 1996; Pinton et al., 1998; Lin et al., 1999). The Golgi seems to handle $\mathrm{Ca}^{2+}$ differently dependent on its sub-compartments. Whilst cis- and medial Golgi compartments contain the SERCA ATPase and $\mathrm{IP}_{3}$ receptors, the trans Golgi takes $\mathrm{Ca}^{2+}$ up exclusively via SPCA1 (secretory pathway $\mathrm{Ca}^{2+}$-ATPase isoform 1 ), and at least in some cells contains ryanodine receptors (Lissandron et al., 2010). Thus, the Golgi can serve as a $\mathrm{Ca}^{2+}$ store responding to local $\mathrm{Ca}^{2+}$. induced $\mathrm{Ca}^{2+}$ release or to second messengers such as cyclic $\mathrm{ADP}$ ribose (CADPR) and nicotinic acid adenine dinucleotide phosphate (NAADP) which have been shown to activate ryanodine receptors (Fliegert et al., 2007). Decreasing $\mathrm{Ca}^{2+}$ in the trans-Golgi complex alters the structure of the entire Golgi apparatus, with effects on sorting of proteins to the plasma membrane through the secretory pathway (Lissandron et al., 2010; Micaroni, 2012). For example, depletion of SPCA1 has been shown to disrupt polarized trafficking, impairing neuronal differentiation, and the generation of functional neurites (Sepúlveda et al., 2009). The mechanism by which intraluminal $\mathrm{Ca}^{2+}$ in the Golgi may regulate sorting is starting to emerge. For example, sorting of some secretory proteins has been shown to require actin remodeling by ADF/cofilin, SPCA1, and a soluble Golgiresident $\mathrm{Ca}^{2+}$-binding protein (von Blume et al., 2011, 2012). Sorting may depend on a transient influx of $\mathrm{Ca}^{2+}$ into the trans Golgi induced by the binding of ADF/cofilin to SPCA1, which may facilitate the association of secretory proteins with the Golgi-resident $\mathrm{Ca}^{2+}$-binding protein, acting as a soluble receptor to segregate a subset of secretory proteins (Kienzle and von Blume, 2014). In sum, alterations in intraluminal $\mathrm{Ca}^{2+}$ concentrations can impact both on cellular $\mathrm{Ca}^{2+}$ signaling as well as on Golgi structure and secreted protein cargo sorting (Micaroni, 2012), and it will be interesting to determine whether this may cause cell-autonomous deficits for example by altering the formation and trafficking of small dense-core DA-containing vesicles (Bauerfeind et al., 1995), or non-cell-autonomous events such as altering the secretion of neurotrophic factors with downstream effects on dopaminergic cell survival (Kordower and Bjorklund, 2013).

$\mathrm{Ca}^{2+}$ is also stored in a variety of acidic organelles (Patel and Docampo, 2010). Acidic organelles containing $\mathrm{Ca}^{2+}$ include endosomes, lysosomes, lysosome-related organelles and secretory granules. Amongst acidic organelles, lysosomes probably comprise the most prominent $\mathrm{Ca}^{2+}$ stores, and may contain an average free $\mathrm{Ca}^{2+}$ concentration in the range of $500 \mu \mathrm{M}$, similar to the $\mathrm{Ca}^{2+}$ concentration within the ER (Lloyd-Evans et al., 2008). $\mathrm{Ca}^{2+}$ uptake into lysosomes is thought to be mediated by pumps. Indeed, purified lysosomes from neutrophils, fibroblasts, and rat liver have been shown to take up $\mathrm{Ca}^{2+}$ in an ATP-dependent manner (Klempner, 1985; Lemons and Thoene, 1991; Ezaki et al., 1992; Adachi et al., 1996). The molecular nature of the lysosomal $\mathrm{Ca}^{2+}$-ATPase remains to be determined, even though some data indicate that it may be driven by SERCA3 (López et al., 2005). Alternatively, $\mathrm{Ca}^{2+}$ loading into lysosomes has been suggested to involve $\mathrm{ER} \mathrm{Ca}^{2+}$ leak, such that small fluctuations in ER $\mathrm{Ca}^{2+}$ levels may cause large effects on lysosomal $\mathrm{Ca}^{2+}$ load (Bezprozvanny, 2012). Acidic stores also possess $\mathrm{Ca}^{2+}$-permeable channels such as $\mathrm{IP}_{3} /$ ryanodine receptors, TRP channels (transient receptor potential channel superfamily), and TPCs (two-pore channels), which are members of the TRP channel superfamily as well (Figure 1). TPC channels located on endosomes and lysosomes have been reported to be targets for NAADP, the most potent $\mathrm{Ca}^{2+}$ mobilizing messenger (Churchill et al., 2002; Guse and Lee, 2008). However, they do not directly bind to NAADP (Lin-Moshier et al., 2012; Walseth et al., 2012), and their gating properties and ion selectivity have recently been questioned (Wang et al., 2012; Cang et al., 2013). This may be due to the fact that they can heterodimerize in-between themselves as well as with a subset of TRP channels, which are gated by NAADP as well (Patel and Docampo, 2010), and further work will be necessary to elucidate how second messengers such as NAADP may trigger $\mathrm{Ca}^{2+}$ release from acidic organelles, and the precise channels involved.

Lysosomal impairments seem intricately linked to PD pathogenesis. Lysosomes are the primary degradative organelle in all cell types, and their function is particularly important in non-dividing cells such as neurons. Several diseases associated with lysosomal dysfunction (lysosomal storage diseases) have been identified, and many of them affect brain function. Conversely, many neurodegenerative diseases also exhibit lysosomal dysfunction (Schultz et al., 2011). Lysosomal impairments are observed in sporadic PD brain and toxic as well as genetic rodent models of PD-related neurodegeneration (Dehay et al., 2013). The mechanisms involved may be varied, including defects in the lysosomal delivery of enzymes required for degradation, defects in lysosomal acidification or altered intralysosomal $\mathrm{Ca}^{2+}$ handling. Importantly, the lysosomal degradative system is characterized by many vesicular fusion events along the endocytic pathway which depend on intraluminal $\mathrm{Ca}^{2+}$, and lysosomal $\mathrm{Ca}^{2+}$ is also required for luminal content condensation (Pryor et al., 2000; Luzio et al., 2007). Whilst precise $\mathrm{Ca}^{2+}$ imaging experiments will be required to determine whether SNc neurons display alterations in intralysosomal $\mathrm{Ca}^{2+}$ levels, such lysosomal $\mathrm{Ca}^{2+}$ dyshomeostasis is expected to cause impaired turnover of dysfunctional mitochondria, which would further aggravate mitochondria-derived oxidant stress in vulnerable neurons.

In the context of proteostasis, it is also worthy considering effects of altered intracellular $\mathrm{Ca}^{2+}$ levels on autophagy, a process employed by cells to get rid of protein aggregates and defunct organelles, and deficits of which are also clearly implicated in PD (Lynch-Day etal., 2012). There is some controversy as to whether increases in $\mathrm{Ca}^{2+}$ promote or inhibit autophagy. This may be due to the subcellular localization of the source of the $\mathrm{Ca}^{2+}$ signal and may also depend on cellular state (Decuypere et al., 2011). Under normal conditions, the $\mathrm{IP}_{3}$ receptor-mediated $\mathrm{Ca}^{2+}$ transfer from the ER to mitochondria, which maintains 
mitochondrial ATP production, seems to inhibit autophagy. In contrast, an increase in cytosolic $\mathrm{Ca}^{2+}$ concentrations can stimulate autophagy (Figure 1; Decuypere et al., 2011). In both cases, this may involve the activity of AMPK, which is activated when cellular ATP levels drop and/or when cytosolic $\mathrm{Ca}^{2+}$ levels increase. Activation of autophagy, combined with a decrease in lysosomal degradative capacity, may then lead to the observed accumulation of autolysosomal structures observed in PD brains (Anglade et al., 1997).

\section{PD, AGING, RISK FACTORS, AND GENETICS}

Age is clearly the single strongest risk factor for PD. The physiological properties of SNc DA neurons indicate that they will be at a higher risk of age-related cell death due to their enhanced burden of $\mathrm{Ca}^{2+}$ handling. Indeed, these neurons seem to be lost at a higher rate (5-10\% every 10 years) than many other neurons in the brain, some of which do not display significant loss over 6070 years (Stark and Pakkenberg, 2004). This means that we may all develop PD if we live long enough. Environmental and genetic factors may then dictate which people become symptomatic (Sulzer, 2007). Environmental factors may further alter intracellular $\mathrm{Ca}^{2+}$ handling, or may impact upon downstream cellular events triggered by $\mathrm{Ca}^{2+}$ dyshomeostasis, playing either protective or damaging roles. As mentioned above, for example toxins known to cause PD increase mitochondrial oxidant stress, thus impacting upon the same pathway already affected in vulnerable neurons.

Similarly, genetic forms of PD would be expected to converge on pathways affected by altered intracellular $\mathrm{Ca}^{2+}$ handling. Familial mutations in a variety of genes, with either autosomal-recessive (parkin, PINK1, DJ-1) or autosomal-dominant [( $\alpha$-synuclein, leucine-rich repeat kinase (2LRRK2)] inheritance account for approximately 10\% of PD cases (Trinh and Farrer, 2013). Of those, parkin, PINK1, and DJ-1 are clearly implicated in mitochondrial homeostasis and $\mathrm{Ca}^{2+}$ handling (Scarffe et al., 2014). For example, DJ-1 seems to protect against mitochondrial oxidant stress evoked by pacemaking in dopaminergic neurons by interfering with mitochondrial uncoupling in response to calcium-induced stress (Guzman et al., 2010). Depletion of DJ-1 seems to decrease expression of certain mitochondrial uncoupling proteins, even though the underlying mechanism(s) remain to be determined. PINK1 has been proposed to contribute to maintaining bioenergetic function of mitochondria by regulating $\mathrm{Ca}^{2+}$ efflux via the $\mathrm{Na}^{+} / \mathrm{Ca}^{2+}$ exchanger, and PINK1 deficiency was reported to cause mitochondrial $\mathrm{Ca}^{2+}$ overload, resulting in mitochondrial oxidant stress (Gandhi et al., 2009). Other studies indicate that PINK1 deficiency is associated with mitochondrial fragmentation, decreased membrane potential and decreased agonist-stimulated $\mathrm{Ca}^{2+}$ entry, thus pinpointing to a role for PINK1 in mitochondrial $\mathrm{Ca}^{2+}$ uptake rather than $\mathrm{Ca}^{2+}$ extrusion, and concomitant decreased ATP production (Heeman et al., 2011). Similarly, parkin deficiency has been reported to cause mitochondrial fragmentation and ER-mitochondria $\mathrm{Ca}^{2+}$ crosstalk, thus affecting cellular bioenergetics (Cali etal., 2013). Both parkin and PINK1 cooperate to regulate mitochondrial quality control events such as fission and fusion, degradation of defunct mitochondria by autophagy (mitophagy), mitochondrial transport, and biogenesis (Scarffe etal., 2014). Whilst the molecular mechanism(s) at present remain sketchy, these three proteins seem to be implicated in the same $\mathrm{Ca}^{2+}$-mediated pathway which is already compromised in sporadic PD (Figure 1).

Other proteins implicated in familial PD such as $\alpha$-synuclein and LRRK2 have been consistently shown to cause dysfunction of the autophagy/lysosomal degradation system (Figure 1; Manzoni and Lewis, 2013), but how they may impact upon ER-mitochondrial $\mathrm{Ca}^{2+}$ handling and mitochondrial oxidant stress is less clear. Autosomal-dominant mutations in LRRK2 have been shown to cause deficits in $\mathrm{Ca}^{2+}$ homeostasis, leading to mitochondrial depolarization and enhanced mitophagy, which can be prevented by L-type $\mathrm{Ca}^{2+}$ channel inhibitors (Papkovskaia et al., 2012; Cherra et al., 2013). Greater levels of mtDNA damage can be observed in LRRK2 mutant patient cells as compared to healthy subjects (Sanders et al., 2014), but whether this is due to altered mitochondrial $\mathrm{Ca}^{2+}$ handling remains to be determined.

Apart from directly affecting mitochondrial $\mathrm{Ca}^{2+}$ handling, gene products involved in familial PD may also affect $\mathrm{Ca}^{2+}$ homeostasis in other intracellular organelles such as ER, Golgi, or lysosomes, with downstream effects on proteostasis and protein aggregation. Precise $\mathrm{Ca}^{2+}$ imaging experiments in the context of both sporadic and familial PD models will be required to reveal possible alterations in intracellular $\mathrm{Ca}^{2+}$ handling by these distinct organelles. For example, altered lysosomal $\mathrm{Ca}^{2+}$ levels may be responsible for the observed changes in lysosomal morphology, clustering, and degradative capacity described for mutant LRRK2-expressing cells (MacLeod et al., 2006; Tong et al., 2010; Dodson et al., 2012; Gómez-Suaga et al., 2012; Orenstein et al., 2013). Such changes, concomitant with an increase in cytosolic $\mathrm{Ca}^{2+}$ levels (Gómez-Suaga et al., 2012), may lead to aberrations in autophagic clearance, followed by a deficit in proteostasis. Impaired proteostasis in the presence of mutant $\alpha$-synuclein has recently been shown to indirectly increase mitochondrial oxidant stress, suggesting that proteostatic extra-mitochondrial stress may be additive with mitochondrial oxidant stress observed in SNc DA neurons (Figure 1; Dryanovski et al., 2013). Whilst the mechanism(s) by which this occurs requires further investigation, it seems to involve NADPH oxidase activity. These data indicate that extramitochondrial oxidant stress may significantly contribute to $\mathrm{PD}$, such that reverting proteostasis deficits may also be therapeutically beneficial in slowing down PD progression. In this context, Golgi-derived proteostasis effects may be worth considering as well, and may underlie altered risk for sporadic (Beilina et al., 2014) as well as familial PD, where Golgi phenotypes have been observed upon mutant $\alpha$-synuclein and LRRK2 expression (Lin et al., 2009), even though whether this is related to altered $\mathrm{Ca}^{2+}$ handling in the Golgi remains to be determined. In sum, $\mathrm{Ca}^{2+}$ dyshomeostasis seems to be central towards our understanding of both sporadic and familial PD, and can affect a plethora of cellular events related to mitochondrial bioenergetics and oxidant stress as well as proteostasis (at the level of the ER, Golgi, and lysosomes) which may in turn increase extramitochondrialderived oxidant stress to further threaten the viability of affected neurons. 


\section{NOVEL HOPES FOR TREATMENT OPTIONS?}

The above-mentioned findings indicate that L-type $\mathrm{Ca}^{2+}$ channel antagonists may be viable therapeutic targets in the early stages of PD. There are oral antagonists [dihydropyridines (DHP)] available, with good blood-brain barrier permeability and a long record of safe use in humans. Adult SNc DA neurons can compensate for L-type $\mathrm{Ca}^{2+}$ channel antagonism and continue pacemaking (Chan etal., 2007), and mice do not show obvious motor, learning, or cognitive deficits when treated with L-type $\mathrm{Ca}^{2+}$ channel antagonists (Bonci et al., 1998), suggesting that these compounds do not alter the functional activity of SNc DA neurons. Indeed, several studies in humans indicate that these compounds diminish the risk of developing PD (Becker et al., 2008; Ritz et al., 2010; Pasternak et al., 2012). However, they do not seem to slow progression of PD (Marras et al., 2012), maybe because of their relatively poor potency against Cav1.3 L-type $\mathrm{Ca}^{2+}$ channels, or because other factors may become more prominent during disease manifestation. Such factors may in part derive from alterations in intracellular $\mathrm{Ca}^{2+}$ stores, with the resultant varied downstream effects on cellular proteostasis.

Much work remains to be done before gaining a clearer understanding of the role of $\mathrm{Ca}^{2+}$ dysregulation in the pathogenesis of PD. It is becoming increasingly clear that abnormal $\mathrm{Ca}^{2+}$ handling may have pleiotropic effects on a variety of intracellular events resulting in mitochondrial oxidant stress, deficits in ER proteostasis, endolysosomal/autophagic trafficking and alterations in Golgi function which require further investigation. Thus, whilst L-type $\mathrm{Ca}^{2+}$ channel antagonists may attack the source of the problem, improving the deteriorated cellular functions of mitochondria, ER, lysosomes, or Golgi may be an efficient complementary strategy to attack the varied downstream effects of the increased burden of handling intracellular $\mathrm{Ca}^{2+}$ in vulnerable neurons. Maybe a feasible future therapeutic strategy should not involve a "hithard" principle employed for example to treat cancer patients, but rather a "hit-softly, continue hitting, and hit at multiple places at a time" principle aimed at correcting a combination of cellular deficits derived from improper $\mathrm{Ca}^{2+}$ handling employing combination-type therapies.

\section{ACKNOWLEDGMENTS}

We are grateful for the financial support of our work by the Spanish Ministry of Economy and Competitiveness (BFU2011-29899), the Junta de Andalucia (grant number CTS 6816), and the Michael J. Fox Foundation. Pilar Rivero-Ríos was supported by CEI Biotic Granada (CAEP2-13).

\section{REFERENCES}

Adachi, T., Arai, K., and Ohkuma, S. (1996). A comparative study of $\left(\mathrm{Ca}^{2+}\right.$ $\mathrm{Mg}^{2+}$ )-ATPase on the lysosomal membrane and ecto-ATPase on the plasma membrane from rat liver. Biol. Pharm. Bull. 19, 1291-1297. doi: 10.1248/bpb. 19.1291

Anglade, P., Vyas, S., Javoy-Agid, F., Herrero, M. T., Michel, P. P., Marquez, J., et al. (1997). Apoptosis and autophagy in nigral neurons of patients with Parkinson's disease. Histol. Histopathol. 12, 25-31.

Augustine, G. J., Santamaria, F., and Tanaka, K. (2003). Local calcium signaling in neurons. Neuron 40, 331-346. doi: 10.1016/S0896-6273(03)00639-1

Bauerfeind, R., Jelinek, R., Hellwig, A., and Huttner, W. B. (1995). Neurosecretory vesicles can be hybrids of synaptic vesicles and secretory granules. Proc. Natl. Acad. Sci. U.S.A. 92, 7342-7346. doi: 10.1073/pnas.92. 16.7342

Becker, C., Jick, S. S., and Meier, C. R. (2008). Use of antihypertensives and the risk of Parkinson disease. Neurology 70, 1438-1444. doi: 10.1212/01.wnl.0000303818.38960.44

Beilina, A., Rudenko, I. N., Kaganovich, A., Civiero, L., Chau, H., Kalia, S. K., et al. (2014). Unbiased screen for interactors of leucine-rich repeat kinase 2 supports a common pathway for sporadic and familial Parkinson disease. Proc. Natl. Acad. Sci. U.S.A. 111, 2626-2631. doi: 10.1073/pnas.1318306111

Bender, A., Krishnan, K. J., Morris, C. M., Taylor, G. A., Reeve, A. K., Perry, R. H., et al. (2006). High levels of mitochondrial DNA deletions in substantia nigra neurons in aging and Parkinson disease. Nat. Genet. 38, 515-517. doi: 10.1038/ ng1769

Berridge, M. J. (2002). The endoplasmic reticulum: a multifunctional signaling organelle. Cell Calcium 32, 235-249. doi: 10.1016/S01434160020 01823

Berridge, M. J., Lipp, P., and Bootman, M. D. (2000). The versatility and universality of calcium signalling. Nat. Rev. Mol. Cell Biol. 1, 11-21. doi: 10.1038/350 36035

Betarbet, R., Sherer, T. B., MacKenzie, G., Garcia-Osuna, M., Panov, A. V., and Greenamyre, J. T. (2000). Chronic systemic pesticide exposure reproduces features of Parkinson's disease. Nat. Neurosci. 3, 1301-1306. doi: 10.1038/81834

Bezprozvanny, I. (2012). Presenilins: a novel link between intracellular calcium signaling and lysosomal function? J. Cell Biol. 198, 7-10. doi: 10.1083/jcb.2012 06003

Bonci, A., Grillner, P., Mercuri, N. B., and Bernardi, G. (1998). L-type calcium channels mediate a slow excitatory synaptic transmission in rat midbrain dopaminergic neurons. J. Neurosci. 18, 6693-6703.

Braak, H., Ghebremedhin, E., Rueb, U., Bratzke, H., and Del Tredici, K. (2004). Stages in the development of Parkinson's disease-related pathology. Cell Tissue Res. 318, 121-134. doi: 10.1007/s00441-004-0956-9

Cali, T., Ottolini, D., and Brini, M. (2011). Mitochondria, calcium, and endoplasmic reticulum stress in Parkinson's disease. Biofactors 37, 228-240. doi: 10.1002/biof.159

Cali, T., Ottolini, D., Negro, A., and Brini, M. (2013). Enhanced parkin levels favor ER-mitochondria crosstalk and guarantee $\mathrm{Ca}^{2+}$ transfer to sustain cell bioenergetics. Biochim. Biophys. Acta 1832, 495-508. doi: 10.1016/j.bbadis.2013. 01.004

Cang, C., Zhou, Y., Navarro, B., Seo, Y. J., Aranda, K., Shi, L., et al. (2013). mTOR regulates lysosomal ATP-sensitive two-pore $\mathrm{Na}^{+}$channels to adapt to metabolic state. Cell 152, 778-790. doi: 10.1016/j.cell.2013.01.023

Chan, C. S., Guzman, J. N., Ilijic, E., Mercer, J. N., Rick, C., Thatch, T., et al. (2007). 'Rejuvenation' protects neurons in mouse models of Parkinson's disease. Nature 447, 1081-1086. doi: 10.1038/nature05865

Cherra, S. J. III, Steer, E., Gusdon, A. M., Kiselyov, K., and Chu, C. T. (2013). Mutant LRRK2 elicits calcium imbalance and depletion of dendritic mitochondria in neurons. Am. J. Pathol. 182, 474-484. doi: 10.1016/j.ajpath.2012. 10.027

Choi, Y. M., Kim, S. H., Chung, S., Uhm, D. Y., and Park, M. K. (2006). Regional interaction of endoplasmic reticulum $\mathrm{Ca}^{2+}$ signals between soma and dendrites through rapid luminal $\mathrm{Ca}^{2+}$ diffusion. J. Neurosci. 26, 12137-12136. doi: 10.1523/JNEUROSCI.3158-06.2006

Churchill, G. C., Okada, Y., Thomas, J. M., Genazzani, A. A., Patel, S., and Galione, A. (2002). NAADP mobilizes $\mathrm{Ca}^{2+}$ from reserve granules, lysosomerelated organelles, in sea urchin eggs. Cell 111, 703-708. doi: 10.1016/S00928674(02)01082-6

Csordas, G., Renken, C., Varnai, P., Walter, L., Weaver, D., Buttle, K. F., et al. (2006). Structural and functional features and significance of the physical linkage between ER and mitochondria. J. Cell Biol. 174, 915-921. doi: 10.1083/jcb.200 604016

Damier, P., Hirsch, E. C., Agid, Y., and Graybiel, A. M. (1999). The substantia nigra of the human brain. II. Patterns of loss of dopamine-containing neurons in Parkinson's disease. Brain 122, 1437-1448. doi: 10.1093/brain/122.8.1437

Decuypere, J.-P., Bultynck, G., and Parys, J. B. (2011). A dual role for $\mathrm{Ca}^{2+}$ in autophagy regulation. Cell Calcium 50, 242-250. doi: 10.1016/j.ceca.2011.04.001 Dehay, B., Martinez-Vicente, M., Caldwell, G. A., Caldwell, K. A., Yue, Z., Cookson, M. R., et al. (2013). Lysosomal impairment in Parkinson's disease. Mov. Disord. 28, 725-732. doi: $10.1002 / \mathrm{mds} .25462$ 
de Lau, L. M., Giesbergen, P. C., de Rijk, M. C., Hofman, A., Koudstaal, P. J., and Breteler, M. M. (2004). Incidence of parkinsonism and Parkinson disease in a general population: the Rotterdam Study. Neurology 63, 1240-1244. doi: 10.1212/01.WNL.0000140706.52798.BE

de Rijk, M. C., Tzourio, C., Breteler, M., Dartigues, J. F., Amaducci, L., Lopez-Pousa, S., et al. (1997). Prevalence of parkinsonism in Parkinson's disease in Europe: the EUROPARKINSON collaborative study. European community concerted action on the epidemiology of Parkinson's disease. J. Neurol. Neurosurg. Psychiatry 62, 10-15. doi: 10.1136/jnnp.62.1.10

Dodson, M. W., Zhang, T., Jiang, C., Chen, S., and Guo, M. (2012). Roles of the Drosophila LRRK2 homolog in rab7-dependent lysosomal positioning. Hum. Mol. Genet. 21, 1350-1363. doi: 10.1093/hmg/ddr573

Dryanovski, D. I., Guzman, J. N., Xie, Z., Galteri, D. J., Volpicelli-Daley, L. A., Lee, V. M., et al. (2013). Calcium entry and $\alpha$-synuclein inclusions elevate dendritic mitochondrial oxidant stress in dopaminergic neurons. J. Neurosci. 33, 10154 10164. doi: 10.1523/JNEUROSCI.5311-12.2013

Egan, M. E., Glockner-Pagel, J., Ambrose, C. A., Cahill, P. A., Pappoe, L., Balamuth, N., et al. (2002). Calcium-pump inhibitors induce functional surface expression of Delta F508-CFTR protein in cystic fibrosis epithelial cells. Nat. Med. 8, 485-492. doi: 10.1038/nm0502-485

Egan, M. E., Pearson, M., Weiner, S. A., Rajendran, V., Rubin, D., Glöckner-Pagel, J., et al. (2004). Curcumin, a major constituent of turmeric, corrects cystic fibrosis defects. Science 304, 600-602. doi: 10.1126/science.1093941

Ezaki, J., Himeno, M., and Kato, K. (1992). Purification and characterization of $\left(\mathrm{Ca}^{2+}-\mathrm{Mg}^{2+}\right)$-ATPase in rat liver lysosomal membranes. J. Biochem. 112, 33-39.

Fan, J., Hu, Z., Zeng, L., Lu, W., Tang, X., Zhang, J., et al. (2008). Golgi apparatus and neurodegenerative diseases. Int. J. Dev. Neurosci. 26, 523-534. doi: 10.1016/j.ijdevneu.2008.05.006

Fahn, S. (2005). Does levodopa slow or hasten the rate of progression of Parkinson's disease? J. Neurol. 252(Suppl. 4), IV37-IV42. doi: 10.1007/s00415-0054008-5

Fliegert, R., Gasser, A., and Guse, A. H. (2007). Regulation of calcium signalling by adenine-based second messengers. Biochem. Soc. Trans. 35, 109-114. doi: 10.1042/BST0350109

Foehring, R. C., Zhang, X. F., Lee, J. C., and Callaway, J. C. (2009). Endogenous calcium buffering capacity of substantia nigral dopamine neurons. J. Neurophysiol. 102, 2326-2333. doi: 10.1152/jn.00038.2009

Fujita, Y., Ohama, E., Takatama, M., Al-Sarraj, S., and Okamoto, K. (2006). Fragmentation of Golgi apparatus of nigral neurons with alpha-synuclein-positive inclusions in patients with Parkinson's disease. Acta Neuropathol. 112, 261-265. doi: 10.1007/s00401-006-0114-4

Gandhi, S., Wood-Kaczmar, A., Yao, Z., Plun-Favreau, H., Deas, E., Klupsch, K., etal. (2009). PINK1-associated Parkinson's disease is caused by neuronal vulnerability to calcium-induced cell death. Mol. Cell 33, 627-638. doi: 10.1016/j.molcel.2009.02.013

German, D. C., Manaye, K. F., Sonsalla, P. K., and Brooks, B. A. (1992). Midbrain dopaminergic cell loss in Parkinson's disease and MPTP-induced parkinsonism: sparing of calbindin-D28k-containing cells. Ann. N.Y. Acad. Sci. 648, 42-62. doi: 10.1111/j.1749-6632.1992.tb24523.x

Goldberg, J. A., Guzman, J. N., Estep, C. M., Ilijic, E., Kondapalli, J., SanchezPadilla, J., et al. (2012). Calcium entry induces mitochondrial oxidant stress in vagal neurons at risk in Parkinson's disease. Nat. Neurosci. 15, 1414-1421. doi: 10.1038/nn.3209

Gómez-Suaga, P., Luzón-Toro, B., Churamani, D., Zhang, L., Bloor-Young, D., Patel, S., et al. (2012). Leucine-rich repeat kinase 2 regulates autophagy through a calcium-dependent pathway involving NAADP. Hum. Mol. Genet. 21, 511-525. doi: $10.1093 / \mathrm{hmg} / \mathrm{ddr} 481$

Grace, A. A., and Bunney, B. S. (1983). Intracellular and extracellular electrophysiology of nigral dopaminergic neurons-2. Action potential generating mechanisms and morphological correlates. Neuroscience 10, 317-331. doi: 10.1016/0306-4522(83)90136-7

Greenamyre, J. T., and Hastings, T. G. (2004). Parkinson's-divergent causes, convergent mechanisms. Science 304, 1120-1122. doi: 10.1126/science.10 98966

Guerreiro, S., Toulorge, D., Hirsch, E., Marien, M., Sokoloff, P., and Michel, P. P. (2008). Paraxanthine, the primary metabolite of caffeine, provides protection against dopaminergic cell death via stimulation of ryanodine receptor channels. Mol. Pharmacol. 74, 980-989. doi: 10.1124/mol.108.048207
Guse, A. H., and Lee, H. C. (2008). NAADP: a universal $\mathrm{Ca}^{2+}$ trigger. Sci. Signal. 1:re10. doi: 10.1126/scisignal.144re10

Guzman, J. N., Sanchez-Padilla, J., Chan, C. S., and Surmeier, D. J. (2009). Robust pacemaking in substantia nigra dopaminergic neurons. J. Neurosci. 29, 1101111019. doi: 10.1523/JNEUROSCI.2519-09.2009

Guzman, J. N., Sanchez-Padilla, J., Wokosin, D., Kondapalli, J., Ilijic, E., Schumacker, P. T., et al. (2010). Oxidant stress evoked by pacemaking in dopaminergic neurons is attenuated by DJ-1. Nature 468, 696-700. doi: 10.1038/nature 09536

Heeman, B., Van den Haute, C., Aelvoet, S. A., Valsecchi, F., Rodenburg, R. J., Reumers, V., et al. (2011). Depletion of PINK1 affects mitochondrial metabolism, calcium homeostasis and energy maintenance. J. Cell Sci. 124, 1115-1125. doi: $10.1242 /$ jcs. 078303

Henchcliffe, C., and Beal, M. F. (2008). Mitochondrial biology and oxidative stress in Parkinson disease pathogenesis. Nat. Clin. Pract. Neurol. 4, 600-609. doi: 10.1038/ncpneuro0924

Ito, H., Goto, S., Sakamoto, S., and Hirano, A. (1992). Calbindin-D28k in the basal ganglia of patients with parkinsonism. Ann. Neurol. 32, 543-550. doi: 10.1002/ana.410320410

Jenner, P. (2001). Parkinson's disease, pesticides and mitochondrial dysfunction. Trends Neurosci. 24, 245-247. doi: 10.1016/S0166-2236(00) 01789-6

Kaufman, R. J., and Malhotra, J. D. (2014). Calcium trafficking integrates endoplasmic reticulum function with mitochondrial bioenergetics. Biochim. Biophys. Acta doi: 10.1016/j.bbamcr.2014.03.022 [Epub ahead of print].

Keeney, P. M., Xie, J., Capaldi, R. A., and Bennett, J. P. Jr. (2006) Parkinson's disease brain mitochondrial complex I has oxidatively damaged subunits and is functionally impaired and misassembled. J. Neurosci. 26, 5256-5264. doi: 10.1523/JNEUROSCI.0984-06.2006

Khaliq, Z. M., and Bean, B. P. (2010). Pacemaking in dopaminergic ventral tegmental area neurons: depolarizing drive from background and voltage-dependent sodium conductances. J. Neurosci. 30, 7401-7413. doi: 10.1523/JNEUROSCI.0143-10.2010

Kienzle, C., and von Blume, J. (2014). Secretory cargo sorting at the trans-Golgi network. Trends Cell Biol. doi: 10.1016/j.tcb.2014.04.007 [Epub ahead of print].

Kirichok, Y., Krapivinsky, G., and Clapham, D. E. (2004). The mitochondrial calcium uniporter is a highly selective ion channel. Nature 427, 360-364. doi: 10.1038 /nature 02246

Kish, S.J., Shannak, K., and Hornykiewicz, O. (1988). Uneven pattern of dopamine loss in the striatum of patients with idiopathic Parkinson's disease. Pathophysiologic and clinical implications. N. Engl. J. Med. 318, 876-880. doi: 10.1056/NEJM198804073181402

Klempner, M. S. (1985). An adenosine triphosphate-dependent calcium uptake pump in human neutrophil lysosomes. J. Clin. Invest. 76, 303-310. doi: 10.1172/JCI111961

Kordower, J. H., and Bjorklund, A. (2013). Trophic factor gene therapy for Parkinson's disease. Mov. Disord. 28, 96-109. doi: 10.1002/mds.25344

Kraytsberg, Y., Kudryavtseva, E., McKee, A. C., Geula, C., Kowall, N. W., and Khrapko, K. (2006). Mitochondrial DNA deletions are abundant and cause functional impairment in aged human substantia nigra neurons. Nat. Genet. 38, 518-520. doi: 10.1038/ng1778

LaFerla, F. M. (2002). Calcium dyshomeostasis and intracellular signalling in Alzheimer's disease. Nat. Rev. Neurosci. 3, 862-872. doi: 10.1038/nrn960

Lee, I., Bender, E., Arnold, S., and Kadenbach, B. (2001). New control of mitochondrial membrane potential and ROS formation-a hypothesis. Biol. Chem. 382, 1629-1636. doi: 10.1515/BC.2001.198

Lemons, R. M., and Thoene, J. G. (1991). Mediated calcium transport by isolated human fibroblast lysosomes. J. Biol. Chem. 266, 14378-14382.

Lin, P., Yao, Y., Hofmeister, R., Tsien, R. Y., and Farquhar, M. G. (1999). Overexpression of CALNUC (nucleobindin) increases agonist and thapsigargin releasable $\mathrm{Ca}^{2+}$ storage in the Golgi. J. Cell Biol. 145, 279-289. doi: 10.1083/jcb.145. 2.279

Lin, X., Parisiadou, L., Gu, X. L., Wang, L., Shim, H., Sun, L., et al. (2009). Leucinerich repeat kinase 2 regulates the progression of neuropathology induced by Parkinson's disease-related mutant alpha-synuclein. Neuron 64, 807-827. doi: 10.1016/j.neuron.2009.11.006

Lin-Moshier, Y., Walseth, T. F., Churamani, D., Davidson, S. M., Slama, J. T., Hooper, R., et al. (2012). Photoaffinity labeling of nicotinic acid adenine dinucleotide 
phosphate (NAADP) targets in mammalian cells. J. Biol. Chem. 287, 2296-2307. doi: 10.1074/jbc.M111.305813

Lissandron, V., Podini, P., Pizzo, P., and Pozzan, T. (2010). Unique characteristics of $\mathrm{Ca}^{2+}$ homeostasis of the trans-Golgi compartment. Proc. Natl. Acad. Sci. U.S.A. 107, 9188-9203. doi: 10.1073/pnas.1004702107

Lloyd-Evans, E., Morgan, A. J., He, X., Smith, D. A., Elliot-Smith, E., Sillence, D. J., et al. (2008) Niemann-Pick disease type $\mathrm{C} 1$ is a sphingosine storage disease that causes deregulation of lysosomal calcium. Nat. Med. 14, 1247-1255. doi: $10.1038 / \mathrm{nm} .1876$

Lloyd-Evans, E., and Platt, F. M. (2011). Lysosomal $\mathrm{Ca}^{2+}$ homeostasis: role in pathogenesis of lysosomal storage diseases. Cell Calcium 50, 200-205. doi: 10.1016/j.ceca.2011.03.010

López, J. J., Camello-Almaraz, C., Pariente, J. A., Salido, G. M., and Rosado, J. A. (2005). $\mathrm{Ca}^{2+}$ accumulation into acidic organelles mediated by $\mathrm{Ca}^{2+}$ and vacuolar H+-ATPases in human platelets. Biochem. J. 390, 243-252. doi: 10.1042/BJ20050168

Luzio, J. P., Bright, N. A., and Pryor, P. R. (2007). The role of calcium and other ions in sorting and delivery in the late endocytic pathway. Biochem. Soc. Trans. 35, 1088-1091. doi: 10.1042/BST0351088

Lynch-Day, M. A., Mao, K., Wang, K., Zhao, M., and Klionsky, D. J. (2012) The role of autophagy in Parkinson's disease. Cold Spring Harb. Perspect. Med. 2, a009357. doi: 10.1101/cshperspect.a009357

MacLeod, D., Dowman, J., Hammond, R., Leete, T., Inoue, K., and Abeliovich, A. (2006). The familial Parkinsonism gene LRRK2 regulates neurite process morphology. Neuron 52, 587-593. doi: 10.1016/j.neuron.2006. 10.008

Mann, V. M., Cooper, J. M., Daniel, S. E., Srai, K., Jenner, P., Marsden, C. D., et al. (1994). Complex I, iron, and ferritin in Parkinson's disease substantia nigra. Ann. Neurol. 36, 876-881. doi: 10.1002/ana.410360612

Manzoni, C., and Lewis, P. A. (2013). Dysfunction of the autophagy/lysosomal degradation pathway is a shared feature of the genetic synucleinopathies. FASEB J. 27, 3424-3429. doi: 10.1096/fj.12-223842

Marras, C., Gruneir, A., Rochon, P., Wang, X., Anderson, G., Brotchie, J., et al. (2012). Dihydropyridine calcium channel blockers and the progression of parkinsonism. Ann. Neurol. 71, 362-369. doi: 10.1002/ana.22616

Matzuk, M. M., and Saper, C. B. (1985). Preservation of hypothalamic dopaminergic neurons in Parkinson's disease. Ann. Neurol. 18, 552-555. doi 10.1002/ana.410180507

McCormack, J. G., and Denton, R. M. (1990). The role of mitochondrial $\mathrm{Ca}^{2+}$ transport and matrix $\mathrm{Ca}^{2+}$ in signal transduction in mammalian tissues. Biochim. Biophys. Acta 1018, 287-291. doi: 10.1016/0005-2728(90)90269-A

Micaroni, M. (2012). Calcium around the Golgi apparatus: implications for intracellular membrane trafficking. Adv. Exp. Med. Biol. 740, 439-460. doi: 10.1007/978-94-007-2888-2_18

Michel, P. P., Toulorge, D., Guerreiro, S., and Hirsch, E. C. (2013). Specific needs of dopamine neurons for stimulation in order to survive: implication for Parkinson disease. FASEB J. 27, 3414-3423. doi: 10.1096/fj.12-220418

Morikawa, H., Imani, F., Khodakhah, K., and Williams, J. T. (2000). Inositol 1,4,5triphosphate-evoked responses in midbrain dopamine neurons. J. Neurosci. 20 , RC103.

Mu, T. W., Fowler, D. M., and Kelly, J. W. (2008). Partial restoration of mutant enzyme homeostasis in three distinct lysosomal storage disease cell lines by altering calcium homeostasis. PLoS Biol. 6:e26. doi: 10.1371/journal.pbio.00 60026

Nicholls, D. G. (2008). Oxidative stress and energy crises in neuronal dysfunction. Ann. N.Y. Acad. Sci. 1147, 53-60. doi: 10.1196/annals.1427.002

Orenstein, S. J., Kuo, S. H., Tasset, I., Arias, E., Koga, H., Fernandez-Carasa, I., et al. (2013). Interplay of LRRK2 with chaperone-mediated autophagy. Nat. Neurosci. 16, 394-406. doi: 10.1038/nn.3350

Papkovskaia, T. D., Chau, K. Y., Inesta-Vaquera, F., Papkovsky, D. B., Healy, D. G., Nishio, K., et al. (2012). G2019S leucine-rich repeat kinase 2 causes uncoupling protein-mediated mitochondrial depolarization. Hum. Mol. Genet. 21, $4201-$ 4213. doi: $10.1093 / \mathrm{hmg} / \mathrm{dds} 244$

Paschen, W., and Mengesdorf, T. (2005). Endoplasmic reticulum stress response and neurodegeneration. Cell Calcium 38, 409-415. doi: 10.1016/j.ceca.2005.06.019

Pasternak, B., Svanstrom, H., Nielsen, N. M., Fugger, L., Melbye, M., and Hviid, A. (2012). Use of calcium channel blockers and Parkinson's disease. Am. J. Epidemiol. 175, 627-635. doi: 10.1093/aje/kwr362
Patel, S., and Docampo, R. (2010). Acidic calcium stores open for business: expanding the potential for intracellular $\mathrm{Ca}^{2+}$ signaling. Trends Cell Biol. 20, 277-286. doi: 10.1016/j.tcb.2010.02.003

Petersen, O. H., Michalak, M., and Verkhratsky, A. (2005). Calcium signalling: past, present and future. Cell Calcium 38, 161-169. doi: 10.1016/j.ceca.2005. 06.023

Pinton, P., Giorgi, C., Siviero, R., Zecchini, E., and Rizzuto, R. (2008). Calcium and apoptosis: ER-mitochondria $\mathrm{Ca}^{2+}$ transfer in the control of apoptosis. Oncogene 27, 6407-6418. doi: 10.1038/onc.2008.308

Pinton, P., Pozzan, T., and Rizzuto, R. (1998). The Golgi apparatus is an inositol 1,4,5-trisphosphate-sensitive $\mathrm{Ca} 2+$ store, with functional properties distinct from those of the endoplasmic reticulum. EMBO J. 17, 5298-5308. doi: 10.1093/emboj/17.18.5298

Pryor, P. R., Mullock, B. M., Bright, N. A., Gray, S. R., and Luzio, J. P. (2000). The role of intraorganellar $\mathrm{Ca}^{2+}$ in late endosome-lysosome heterotypic fusion and in the reformation of lysosomes from hybrid organelles. J. Cell Biol. 149, 1053-1062. doi: 10.1083/jcb.149.5.1053

Przedborski, S., Tieu, K., Perier, C., and Vila, M. (2004). MPTP as a mitochondrial neurotoxic model of Parkinson's disease. J. Bioenerg. Biomembr. 36, 375-379. doi: 10.1023/B:JOBB.0000041771.66775.d5

Puopolo, M., Raviola, E., and Bean, B. P. (2007). Roles of subthreshold calcium current and sodium current in spontaneous firing of mouse midbrain dopamine neurons. J. Neurosci. 27, 645-656. doi: 10.1523/JNEUROSCI.434106.2007

Ritz, B., Rhodes, S. L., Qian, L., Schernhammer, E., Olsen, J. H., and Friis, S. (2010). L-type calcium channel blockers and Parkinson disease in Denmark. Ann. Neurol. 67, 600-606. doi: 10.1002/ana.21937

Rizzuto, R. (2001). Intracellular $\mathrm{Ca}^{2+}$ pools in neuronal signalling. Curr. Opin. Neurobiol. 11, 306-311. doi: 10.1016/S0959-4388(00)00212-9

Rizzuto, R., and Pozzan, T. (2006). Microdomains of intracellular $\mathrm{Ca}^{2+}$ : molecular determinants and functional consequences. Physiol. Rev. 86, 369-408. doi: 10.1152/physrev.00004.2005

Sanders, L. H., Laganiere, J., Cooper, O., Mak, S. K., Vu, B. J., Huang, Y. A., et al. (2014). LRRK2 mutations cause mitochondrial DNA damage in iPSCderived neural cells from Parkinson's disease patients: reversal by gene correction. Neurobiol. Dis. 62, 381-386. doi: 10.1016/j.nbd.2013.10.013

Santo-Domingo, J., and Demaurex, N. (2010). Calcium uptake mechanisms of mitochondria. Biochim. Biophys. Acta 1797, 907-912. doi: 10.1016/j.bbabio.2010.01.005

Scarffe, L. A., Stevens, D. A., Dawson, V. L., and Dawson, T. M. (2014). Parkin and PINK1: much more than mitophagy. Trends Neurosci. doi: 10.1016/j.tins.2014.03.004 [Epub ahead of print].

Schapira, A. H. (2008). Mitochondria in the aetiology and pathogenesis of Parkinson's disease. Lancet Neurol. 7, 97-109. doi: 10.1016/S1474-4422(07) 70327-7

Scherer, P. E., Lederkremer, G. Z., Williams, S., Fogliano, M., Baldini, G., and Lodish, H. F. (1996). Cab45, a novel $\mathrm{Ca}^{2+}$-binding protein localized to the Golgi lumen. J. Cell Biol. 133, 257-268. doi: 10.1083/jcb.133.2.257

Schultz, M. L., Tecedor, L., Chang, M., and Davidson, B. L. (2011). Clarifying lysosomal storage diseases. Trends Neurosci. 34, 401-410. doi: 10.1016/j.tins.2011.05.006

Sepúlveda, M. R., Vanoevelen, J., Raeymaekers, L., Mata, A. M., and Wuytack, F. (2009). Silencing the SPCA1 (secretory pathway $\mathrm{Ca}^{2+}$-ATPase isoform 1) impairs $\mathrm{Ca}^{2+}$ homeostasis in the Golgi and disturbs neural polarity. J. Neurosci. 29, 12174-12182. doi: 10.1523/JNEUROSCI.2014-09.2009

Stark, A. K., and Pakkenberg, B. (2004). Histological changes of the dopaminergic nigrostriatal system in aging. Cell Tissue Res. 318, 81-92. doi: 10.1007/s00441004-0972-9

Sulzer, D. (2007). Multiple hit hypotheses for dopamine neuron loss in Parkinson's disease. Trends Neurosci. 30, 244-250. doi: 10.1016/j.tins.2007.03.009

Surmeier, D. J., Guzman, J. N., Sanchez-Padilla, J., and Goldberg, J. A. (2011). The origins of oxidant stress in Parkinson's disease and therapeutic strategies. Antioxid. Redox Signal. 14, 1289-1301. doi: 10.1089/ars.2010.3521

Surmeier, D. J., and Schumacker, P. T. (2013). Calcium, bioenergetics, and neuronal vulnerability in Parkinson's disease. J. Biol. Chem. 288, 10736-10741. doi: 10.1074/jbc.R112.410530

Thayer, D. A., Jan, Y. N., and Jan, L. Y. (2013). Increased neuronal activity fragments the Golgi complex. Proc. Natl. Acad. Sci. U.S.A. 110, 1482-1487. doi: $10.1073 /$ pnas. 1220978110 
Tong, Y., Yamaguchi, H., Giaime, E., Boyle, S., Kopan, R., Kelleher, R. J. III, et al. (2010). Loss of leucine-rich repeat kinase 2 causes impairment of protein degradation pathways, accumulation of alpha-synuclein, and apoptotic cell death in aged mice. Proc. Natl. Acad. Sci. U.S.A. 107, 9879-9884. doi: 10.1073/pnas.10046 76107

Trinh, J., and Farrer, M. (2013). Advances in the genetics of Parkinson disease. Nat. Rev. Neurol. 9, 445-454. doi: 10.1038/nrneurol.2013.132

Verkhratsky, A. (2005). Physiology and pathophysiology of the calcium store in the endoplasmic reticulum of neurons. Physiol. Rev. 85, 201-279. doi: 10.1152/physrev.00004.2004

Vila, M., Ramonet, D., and Perier, C. (2008). Mitochondrial alterations in Parkinson's disease: new clues. J. Neurochem. 107, 317-328. doi: 10.1111/j.14714159.2008.05604.x

von Blume, J., Alleaume, A. M., Cantero-Recasens, G., Curwin, A., CarrerasSureda, A., Zimmermann, T., et al. (2011). ADF/cofilin regulates secretory cargo sorting at the TGN via the $\mathrm{Ca}^{2+}$ ATPase SPCA1. Dev. Cell 20, 652-662. doi: 10.1016/j.devcel.2011.03.014

von Blume, J., Alleaume, A. M., Kienzle, C., Carreras-Sureda, A., Valverde, M. and Malhotra, V. (2012). Cab45 is required for $\mathrm{Ca}^{2+}$-dependent secretory cargo sorting at the trans-Golgi network. J. Cell Biol. 199, 1057-1066. doi: $10.1083 /$ jcb. 201207180

Walseth, T. F., Lin-Moshier, Y., Jain, P., Ruas, M., and Parrington, J., (2012). Photoaffinity labeling of high affinity nicotinic acid adenine dinucleotide phosphate (NAADP)-binding proteins in sea urchin egg. J. Biol. Chem. 287, 2308-2315. doi: 10.1074/jbc.M111.306563
Wang, X., Zhang, X., Dong, X. P., Samie, M., Li, X., Cheng, X., et al. (2012). TPC proteins are phosphoinositide-activated sodium-selective ion channels in endosomes and lysosomes. Cell 151, 372-383. doi: 10.1016/j.cell.2012. 08.036

Zhang, J., Perry, G., Smith, M. A., Robertson, D., Olson, S. J., Graham, D. G., et al. (1999) Parkinson's disease is associated with oxidative damage to cytoplasmic DNA and RNA in substantia nigra neurons. Am. J. Pathol. 154, 1423-1429. doi: $10.1016 /$ S0002-9440(10)65396-5

Conflict of Interest Statement: The authors declare that the research was conducted in the absence of any commercial or financial relationships that could be construed as a potential conflict of interest.

Received: 29 April 2014; accepted: 27 May 2014; published online: 17 June 2014. Citation: Rivero-Ríos P, Gómez-Suaga P, Fdez E and Hilfiker S (2014) Upstream deregulation of calcium signaling in Parkinson's disease. Front. Mol. Neurosci. 7:53. doi: 10.3389/fnmol.2014.00053

This article was submitted to the journal Frontiers in Molecular Neuroscience.

Copyright (c) 2014 Rivero-Ríos, Gómez-Suaga, Fdez and Hilfiker. This is an openaccess article distributed under the terms of the Creative Commons Attribution License (CC BY). The use, distribution or reproduction in other forums is permitted, provided the original author(s) or licensor are credited and that the original publication in this journal is cited, in accordance with accepted academic practice. No use, distribution or reproduction is permitted which does not comply with these terms. 